Araştırma Makalesi - Research Article

\title{
İndirgenmiş Grafen Oksit/Çinko Oksit Kompozitlerin Üretimi ve Süper Kapasitör Uygulamaları
}

\author{
Ayça TANRIVERD $\dot{I}^{1 *}$
}

ÖZ

$\mathrm{Bu}$ çalışmada, indirgenmiş grafen oksit/çinko oksit $(\mathrm{RGO} / \mathrm{ZnO})$ kompozit malzemeleri hidrotermal yöntem kullanılarak sentezlenmiştir. Sentezlenen RGO/ZnO kompozitleri, süper kapasitör uygulamaları için elektrot yapımında kullanılmıştır. RGO/ZnO kompozit malzemeler farklı çinko kaynakları (çinko nitrat, çinko klorür ve çinko asesat) kullanılarak üretilip, farklı çinko tuzların RGO/ZnO elektrotların kapasitans değerleri üzerindeki etkisi araştırılmıştır. RGO/ZnO kompozitlerin karakterizasyonu XRD (X-ışını kırınımı) ve SEM (taramalı elektron mikroskopisi) ile gerçekleştirilmiştir. Üretilen $\mathrm{RGO} / \mathrm{ZnO}$ elektrotların elektrokimyasal özellikleri döngüsel voltametri, elektrokimyasal empedans ve galvanostatik şarj-deşarj testleriyle $6 \mathrm{M} \mathrm{KOH}$ çözeltisi içinde analiz edilmiştir. Yapılan analizler sonucunda; çinko nitrat tuzu kullanılarak elde edilen RGO/ZnO kompozit malzemesi ile oluşturulan elektrodun maksimum spesifik kapasitans değerine $(52,71 \mathrm{~F} / \mathrm{g})$ ulaştığı belirlenmiştir.

1*Sorumlu yazar iletişim: aa.kudret@hotmail.com (https://orcid.org/0000-0002-0658-8576)

Fizik Bölümü, Fen-Edebiyat Fakültesi, Kahramanmaraş Sütçü Imam Üniversitesi, 46100 Kahramanmaraş 


\title{
Production of Reduced Graphene Oxide/Zinc Oxide Composites and Super Capacitor Applications
}

\begin{abstract}
In this work, reduced graphene oxide/zinc oxide ( $\mathrm{RGO} / \mathrm{ZnO})$ composite materials were synthesized by hydrothermal method. Synthesized $\mathrm{RGO} / \mathrm{ZnO}$ composites were used in electrode for super capacitor applications. $\mathrm{RGO} / \mathrm{ZnO}$ composite materials are produced using different zinc sources (zinc nitrate, zinc chloride and zinc acetate) and effect of different zinc salts on capasitans value of $\mathrm{RGO} / \mathrm{ZnO}$ electrodes was investigated. Characterization of $\mathrm{RGO} / \mathrm{ZnO}$ composites was performed with XRD (X-ray diffraction) and SEM (scanning electron microscopy). Electrochemical properties of produced $\mathrm{RGO} / \mathrm{ZnO}$ electrodes were analyzed in $6 \mathrm{M} \mathrm{KOH}$ solution by cyclic voltammetry, electrochemical impedance and galvanostatic charge-discharge. Experimental results showed that $\mathrm{RGO} / \mathrm{ZnO}$ composite electrode obtained by zinc nitrate salt reached maximum specific capacitance $(52,71 \mathrm{~F} / \mathrm{g})$.
\end{abstract}




\section{GİRIŞ}

Gelişmekte olan ülkelerde artan nüfus, sanayileşme ve teknolojinin yaygınlaşması enerjiye olan talebin hızla artmasına sebep olmuştur. Dünyada artan bu enerji ihtiyacı, yeni enerji kaynaklarının gelişmesini ve var olan enerji kaynaklarının daha verimli kullanılması için depolanmasını zorunlu kılmaktadır [1]. Yenilenebilir enerjinin elde edilmesi kadar üretilen enerjinin depolanması da çok büyük önem arz etmektedir. Enerji genel olarak mekaniksel (volan, sıkıştııılmış hava), kimyasal (batarya, hidrojen, yakıt hücreleri) ve elektriksel (süperiletken-manyetik enerji depolama, süper kapasitör) sistemler şeklinde depolanabilir [2].

Son yıllarda bilimsel çalışmalar küçük boyutlarda farklı bataryaların ve yüksek kapasiteli kapasitörlerin oluşturulmasına odaklanmıştır [3]. Lityum-iyon pilleri ve geleneksel kapasitörlerle kıyaslandıklarında, süper kapasitörler binlerce kat daha yüksek güç ve enerji yoğunluğuna, kısa şarj sürelerine ve uzun ömür gibi avantajlara sahip, ideal güç depolayıcı sistemlerdir[4-5].

Süper kapasitörler de yük depolama olayı elektrotlarda gerçekleşmektedir. Süper kapasitörün elektrot malzemesi olarak en çok gözenekli yapılı karbon tabanlı malzemeler (grafen gibi) kullanılmaktadır. Metal oksit ve iletken polimerlerle elde edilen süper kapasitörler karbon tabanlı süper kapasitörlere göre daha yüksek kapasitans değerine sahiptir. Fakat yüksek kapasitans özelliği sergileyen metal oksitlerin $\mathrm{RuO}_{2}$ (çok pahalı) ve $\mathrm{ZnO}, \mathrm{NiO}, \mathrm{MnO}_{2}$ gibi metal oksitlerin iletkenliklerinin düşük olması, iletken polimerlerin düşük döngü ömürlerine sahip olmaları gibi etkenler karbon tabanlı elektrotlar üzerinde çalışmaları yoğunlaştırmıştır. Özellikle asidik ve bazik ortamlarda ve geniş bir sıcaklık aralığında mükemmel kimyasal kararlılık göstermeleri ve çevre dostu olmaları nedeniyle karbon tabanlı malzemeler, elektrokimyasal enerji cihazlarında elektrot malzemesi olarak ilgi çekici hale gelmiştir[6]. Fakat grafen elektrot malzemesi için kullanıldığında en büyük sorunlardan biri, üretim tekniğine bağlı olarak grafen tabanları kümeleşmekte ve bunun sonucu olarak yüzey alanı küçülmektedir [7]. Ayrıca birçok grafen elektrot tek bir tabaka olarak elde edilememekte ve elde edilen grafen tabakalar birçok kimyasal ve topolojik kusurlar içermektedir. Bu kusurları gidermek ve dezavantajların üstesinden gelmek için farklı gruplardaki malzemelerin en iyi özelliklerini bir araya toplamak ya da yeni bir özellik ortaya çıkarmak amacıyla bu malzemelerin birleştirilmesiyle kompozit malzemeler elde edilmektedir.

Kompozit malzemeler üretilirken birçok yöntemden faydalanılmaktadır. Nano boyuta sahip metal oksit partiküllerinin sentezi için; sol-gel, anorganik tuzların hidrolizi, ultrasonik teknik, mikroemülsiyon ve hidrotermal yöntem gibi polar ve apolar çözücü sistemlerinin kullanıldığı çok değişik yöntemler literatürde yer almaktadır. Hidrotermal hariç diğer sentez yöntemlerinde, kristal formda nano boyuta sahip metal oksit partiküllerinin sentezi oldukça yüksek sıcaklıklarda gerçekleştirilmektedir. Diğer yöntemlerle kıyaslandığında, tamamen saf ve kristal yapıda, homojen ve en etkin fotokatalitik aktiviteye sahip nano metal oksit partiküllerinin düşük sıcaklıkta ve kısa sürede sentezlenmesine olanak sağladığından dolayı bu çalışmada nano boyuta sahip metal oksit partiküllerinin sentezi ve grafenin indirgenmesi için hidrotermal yöntem seçilmiştir.

Grafen ve metal oksitlerin tek başına sahip oldukları özellikleri arttırmak için grafen metal oksit malzemeleri oluşturulmaktadır. Çeşitli metal oksitler arasında çinko oksit $(\mathrm{ZnO})$ düşük maliyetli ve çevre dostu olması, $650 \mathrm{Ah} / \mathrm{g}$ yüksek enerji yoğunluğuna sahip olmasından dolayı bu çalışmada süper kapasitörler için elektrot malzemesi olarak seçilmiştir. Literatürde bu konu ile ilgili birçok çalışma bulunmaktadır. Fang ve arkadaşları, süper kapasitörler için elektrot malzemesi olarak sentezledikleri ZnO-grafen nanokompozitlerin 786 F/g spesifik kapasitans değerine ulaştığını tespit etmişlerdir [8]. Benzer şekilde Jayachandiran ve arkadaşları süper kondansatör uygulaması olarak $\mathrm{RGO} / \mathrm{ZnO}$ ve saf $\mathrm{ZnO}$ elektrodu sentezlemiş ve ürettikleri $\mathrm{RGO} / \mathrm{ZnO}$ elektrodun sahip olduğu spesifik kapasitans değerinin $(312 \mathrm{~F} / \mathrm{g})$ saf $\mathrm{ZnO}$ elektroduna kiyasla daha yüksek olduğunu gözlemlemişlerdir [9]. Yine Mohan ve arkadaşları sentezledikleri RGO, $\mathrm{ZnO}$ ve RGO/ZnO kompozit elektrotların kapasitans değerlerini incelemiş ve $\mathrm{RGO} / \mathrm{ZnO}$ elektrotun $(280 \mathrm{~F} / \mathrm{g})$, RGO ve saf $\mathrm{ZnO}$ elektrotlarına göre daha iyi kapasitans özellik sergilediğini belirlemişlerdir [10]. Bu çalışmada diğer çalışmalardan farklı olarak üç farklı çinko kaynağı kullanılarak RGO/ZnO kompozit malzemeleri üretilmiştir. Sentezlenen RGO/ZnO kompozitlerin fiziksel özelliklerindeki değişimin, $\mathrm{RGO} / \mathrm{ZnO}$ elektrotların kapasitans değerleri üzerindeki etkisi araştırılarak mevcut literatüre katkı sağlaması amaçlanmıştır. 


\begin{tabular}{|c|c|c|}
\hline & $\begin{array}{l}\text { BŞEÜ Fen Bilimleri Dergisi } \\
7(1), 201-210,2020\end{array}$ & $\begin{array}{r}\text { BSEU Journal of Science } \\
\text { DOI: } 10.35193 / \text { bseufbd.682266 }\end{array}$ \\
\hline & & 58-7575 (http://dergipark.gov.tr/bseufbd) \\
\hline
\end{tabular}

\section{MATERYAL VE YÖNTEM}

$\mathrm{Bu}$ çalışmada, indirgenmiş grafen oksit/çinko oksit (RGO/ZnO) kompozit malzemeler sentezlenerek süper kapasitörler için elektrot yapımı gerçekleş̧irildi. RGO/ZnO elektrotlar üç aşamada üretildi.

Birinci aşamada; Grafen oksit (GO) garafit tozu kullanılarak Hummers metodu ile sentezlendi [11]. İkinci aşamada; $\mathrm{ZnO}$ nanoparçacıkların üretiminde çinko kaynağı olarak çinko nitrat $\left(\mathrm{Zn}\left(\mathrm{NO}_{3}\right)_{2} \cdot 6 \mathrm{H}_{2} \mathrm{O}\right)$, çinko klorür $\left(\mathrm{ZnCl}_{2}\right)$ ve çinko asetat $\left(\mathrm{Zn}\left(\mathrm{CH}_{3}\right)_{2} \cdot 2 \mathrm{H}_{2} \mathrm{O}\right)$ tuzları kullanıldı. $0,1 \mathrm{M}$ çinko nitrat $\left(\mathrm{Zn}\left(\mathrm{NO}_{3}\right)_{2} \cdot 6 \mathrm{H}_{2} \mathrm{O}\right)$ ve $0,1 \mathrm{M}$ hekzametilen tetramin $\left(\mathrm{C}_{6} \mathrm{H}_{12} \mathrm{~N}_{4}\right) 100 \mathrm{ml}$ saf suda çözülüp, çözelti 30 dakika manyetik karıştırıcı da karıştıııldı. Üretilecek parçacıkların boyutunu küçülttmek için amonyak $\left(\mathrm{NH}_{3}\right)$ damlatılarak çözeltinin $\mathrm{pH} 10$ olacak şekilde ayarlandı. Üretilen $\mathrm{ZnO}$ parçacıkların morfolojisini ve boyutlarını etkileyen $\mathrm{pH}$, sıcaklık gibi faktörler ile ilgili literatür de birçok çalışma mevcuttur [12-16]. Daha sonra bu çözelti teflon kaplı otoklavda $200^{\circ} \mathrm{C}^{\prime}$ de 3 saat bekletilerek $\mathrm{ZnO}$ parçacıklar oluşturuldu. Kendiliğinden oda sıcaklığında soğumaya bırakılan çözelti içinden $\mathrm{ZnO}$ parçacıklar süzülerek alındı. $\mathrm{ZnO}$ parçacıklar saf su ile yıkanarak içindeki organik bileşenlerden kurtulması sağlandı. Sentezlenen $\mathrm{ZnO}$ parçacıklarında bulunan hidroksit fazını ortadan kaldırmak için $450^{\circ} \mathrm{C}$ ' de 1 saat süreyle tavlandı. Aynı uygulamalar çinko klorür $\left(\mathrm{ZnCl}_{2}\right)$ ve çinko asetat $\left.\left(\mathrm{Zn}_{\left(\mathrm{CH}_{3}\right.}\right)_{2} \cdot 2 \mathrm{H}_{2} \mathrm{O}\right)$ tuzları içinde yapıldı. Üçüncü aşamada; $\mathrm{RGO} / \mathrm{ZnO}$ kompozit malzemeler yine hidrotermal yöntem ile sentezlendi. Öncelikle $0,1 \mathrm{~g}$ grafen oksit (GO), $20 \mathrm{ml}$ saf su ve $10 \mathrm{ml}$ etanol $\left(\mathrm{C}_{2} \mathrm{H}_{2} \mathrm{OH}\right)$ çözeltisi içinde ultrasonik banyo yardımıyla 1 saat karıştıııldı. Daha sonra bu çözeltinin içerisine $0,1 \mathrm{~g} \mathrm{ZnO}$ (çinko nitrat tuzu) parçacıkları eklendi ve 2 saat boyunca ultrasonik banyoda karışması için bekletildi. Ardından çözelti teflon kaba konulup otoklav içerisine yerleştirildi. Otoklav kül fırınında $160^{\circ} \mathrm{C}^{\prime}$ de 3 saat bekletildi. Böylece hem GO grafene indirgenmiş hemde kimyasal olarak birbirine bağlanmış RGO/ZnO kompozit malzeme elde edildi. Elde edilen kompozit malzeme süzülüp saf su ile yıkandıktan sonra oda sıcaklığında kurutuldu. Aynı uygulamalar çinko klorür $\left(\mathrm{ZnCl}_{2}\right)$ ve çinko asetat $\left(\mathrm{Zn}\left(\mathrm{CH}_{3}\right)_{2} .2 \mathrm{H}_{2} \mathrm{O}\right)$ tuzlarından elde edilen $\mathrm{ZnO}$ parçacıklar içinde yapıldı. RGO/ZnO kompozit malzemelerinin üretim süreçleri ve deneysel mekanizmaların şematik görünümü Şekil 1' de gösterilmiştir.

Elektrot yapımı için elde edilen $\mathrm{RGO} / \mathrm{ZnO}$ kompozit malzemesinden $\% 70$, grafit tozundan $\% 20$ ve politetraflorinetilenden (PTFE) \%10 oranlarında alınarak üzerine butanol damlatıp karışımın macun kıvamına getirilmesi sağlandı. Macun kıvamındaki RGO/ZnO kompozit malzemesi $\mathrm{Ni}$ köpük üzerine $1 \mathrm{~cm}^{2}$ lik alan oluşturacak şekilde sürülüp 24 saat oda sıcaklığında bekletildi.

Üretilen RGO/ZnO kompozit malzemelerin kristal yapısı XRD deseni Philips X'Pert PRO cihazı ve morfolojik yapıları SEM görüntüleri Zeiss EVO 10LS cihazı kullanılarak incelendi. Elde edilen elektrotların kapasitans ölçümleri tipik üç elektrot düzeni kullanılarak Iviumstat potentiostat /galvanostat döngüsel voltametrisi ile gerçekleştirildi. Ölçüm düzeneğinde; $\mathrm{Ni}$ köpük üzerine RGO/ZnO kompozit malzemelerden hazırlanan çalışma elektrodu, standart kalomel elektrottan oluşan referans elektrotu ve platin folyodan oluşan karşıt elektrot kullanıldı. Elektrolit sıvısı olarak 6M KOH (potasyum hidroksit) çözeltisi kullanıldı.

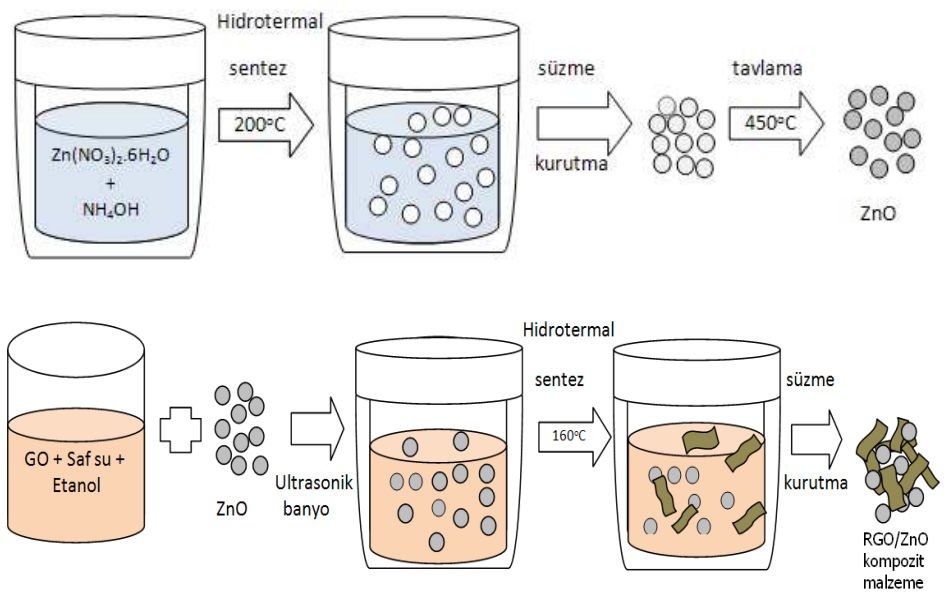

Şekil 1. RGO/ZnO kompozit malzemelerin sentez aşamaları [17] 


\section{BULGULAR VE TARTIŞMA}

\section{A. X-Işınımı Kırınımı (XRD)Sonuçları}

Kompozit malzemelerin kırınım deseni X-1şını difraksiyon (XRD) kullanılarak ölçülmüştür. Kullanılan PhilipsX'pert PRO marka XRD cihazında, çalışma aralığı 40kV, 30mA olarak ayarlanmış ve ölçümler monokromatik $\mathrm{CuK} \alpha$ radyasyonu $(\lambda=0,154056 \mathrm{~nm}$ ) kullanarak yapılmıştır. Farklı çinko kaynakları (çinko nitrat, çinko klorür ve çinko asetat) kullanılarak üretilen RGO/ZnO kompozit malzemelerin XRD desenleri Şekil 2'de verilmiştir. XRD spektrumundan görüldüğü gibi $\mathrm{RGO} / \mathrm{ZnO}$ yapısı; wurtzite $\mathrm{ZnO}$ fazından (PDF-2, referans no:01-079-2205), simonkollite $\left(\mathrm{Zn}(\mathrm{OH})_{8} \mathrm{Cl}_{2} \cdot \mathrm{H}_{2} \mathrm{O}\right)$ olarak adlandırılan çinko hidroksit fazı (PDF-2, referans no:00-076-0922) ve RGO (indirgenmiş grafen oksit) fazının karışımından oluşmaktadır. Elde edilen RGO/ZnO kompozit malzemelerin kırınım desenlerindeki wurtzite $\mathrm{ZnO}$ fazına ait pikler $2 \theta=31.70^{\circ}, 34.13^{\circ}, 36.15^{\circ}, 47.53^{\circ}$ $56.47^{\circ}, 62.82^{\circ}, 66.35^{\circ}, 67.76^{\circ}$ ve $69.03^{\circ}$ olduğu gözlenmiştir. Bu açı değerlerine karşılık gelen düzlemler ise sirasiyla (100), (002), (101), (102), (110), (103), (200), (112) ve (201) olarak belirlenmiştir. $\mathrm{Zn}(\mathrm{OH})_{8} \mathrm{Cl}_{2} \cdot \mathrm{H}_{2} \mathrm{O}$ (çinko hidroksit) fazına ait pikler $2 \theta=32.84^{\circ}, 58.49^{\circ}$ ve $(021)$, (220) düzlemlerinde olduğu gözlenmiştir. Ayrıca Şekil 2'den görüldüğü gibi çinko oksit ve çinko hidroksite ait piklerin oldukça belirgin olarak görülmesine rağmen $2 \theta=25,4^{\circ}$ değerinde RGO'ya ait (002) düzlemi zayıf şekilde görülmektedir. Muhtemelen bu pik $\mathrm{ZnO}$ parçacıkların grafen tabakaları arasına girerek kümeleşmeyi önlemesi ile ortaya çıkan piktir[18-19]. Kompozit malzemeleri oluşturan $\mathrm{ZnO}$ parçacıkların $450^{\circ} \mathrm{C}^{\prime}$ de 1 saat tavlanmasına rağmen yapıda hidroksitli yapı oluşmasının sebebi, hidrotermal metodla kompozit malzeme oluştururken kullanılan GO çözeltisi içine konulan $\mathrm{ZnO}$ yapısının tekrar rehidrazyona uğraması ve simonkollite yapıya dönüşmesidir.

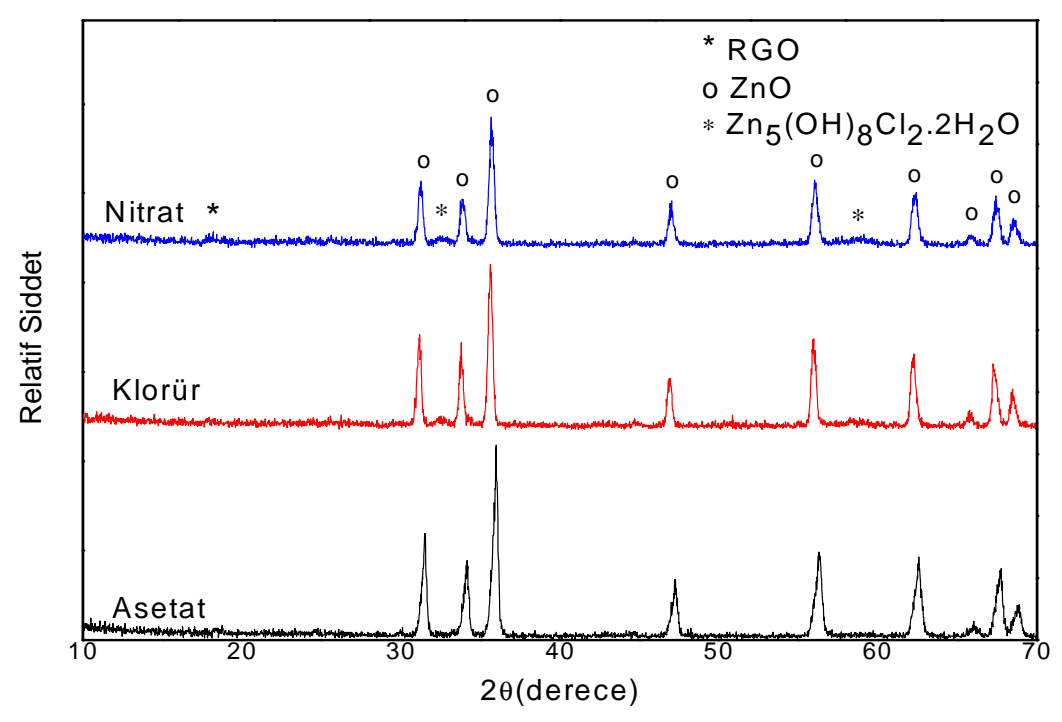

Şekil 2. Üretilen RGO/ZnO kompozit maddelerinin XRD spektrumu

\section{B. Taramalı Elektron Mikroskobu (SEM) Analizleri}

Şekil 3'de RGO/ZnO kompozit malzemelerin SEM görüntüleri bulunmaktadır. SEM fotoğraflarından görüldüğü gibi farklı çinko kaynaklarından elde edilen RGO/ZnO kompozit malzemelerin morfolojik yapılarının oldukça benzer olduğu görülmektedir. SEM görüntüleri incelendiğinde, altıgen plaka benzeri yapıya sahip $\mathrm{ZnO}$ parçacıklar, RGO' nun yüzeyi üzerine rastgele bir şekilde dağılmış ve oksijen içeren gruplar nedeniyle grafen katmanlarının yüzeyine tutunmuşlardır. Grafen tabakalarının tamamen indirgenememesi ve tabakalar arasında arta kalan oksijen atomları ile $\mathrm{ZnO}$ parçacıkların bağlantı yaptı̆̆ı düşünülmektedir. $\mathrm{RGO} / \mathrm{ZnO}$ kompozit malzemelerin üretim sürecinde $\mathrm{Zn}^{+2}$, öncelikle grafen oksit karboksilat anyonları tarafından tutulmuş ve grafen oksit yaprakları arasına yerleşmiştir[20]. Hekzagonal tabaka şeklindeki ZnO parçacıklarının kristal yapısının 


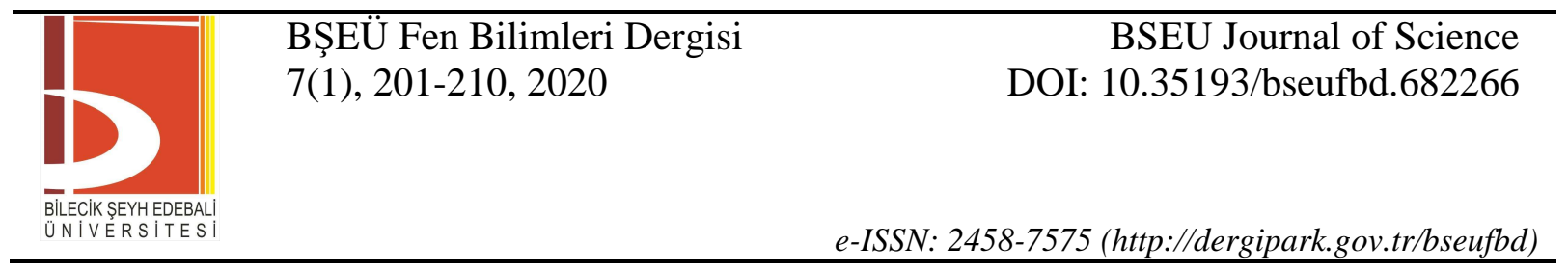

tamamen wurtzite yapı olmayıp hidroksitli yapıyı da içerdiği Şekil 2'deki XRD spektrumunda verilmiştir. SEM fotoğrafları XRD spektrumlarını destekleyecek şekildedir.
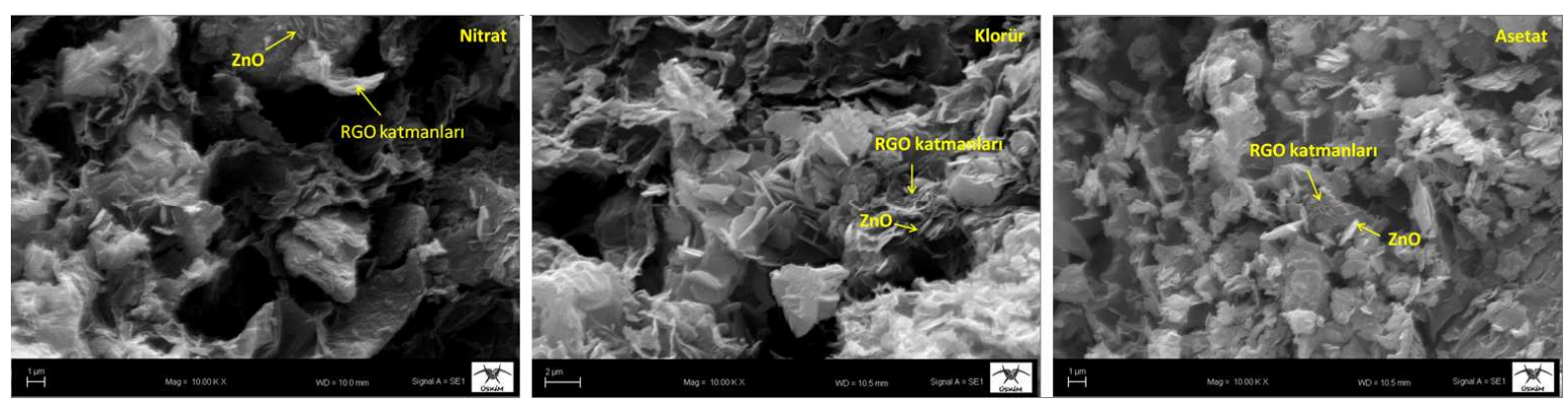

Şekil 3. Üretilen RGO/ZnO kompozit maddelerin SEM görüntüleri

\section{Elektrokimyasal Analiz}

Çinko nitrat, çinko klorür ve çinko asetat tuzları kullanılarak sentezlenen RGO/ZnO kompozit maddelerinden üretilen elektrotların kapasitans, empedans, yükleme/boşalma eğrileri incelenerek elektrokimyasal özellikleri araştırılmıştır. Elektrotların kapasitans ölçümleri döngüsel voltametri (CV) yöntemi ile Iviumstat cihazı kullanılarak belirlenmiştir. Ölçümler $6 \mathrm{M} \mathrm{KOH}$ çözeltisinde, Kalomel referans elektrot kullanılarak 5mV/s tarama hızında oda sıcaklığında gerçekleştirilmiştir. Elektrotların kapasitans değerleri döngüsel voltagram eğrisi kullanılarak $\mathrm{C}=\mathrm{I}_{\text {ort }} /(\mathrm{vx} m)$ eşitliği ile hesaplanmıştır. Bu eşitlikte $\mathrm{I}_{\text {ort }}$ ortalama akım, $v$ tarama hızı ve $m$ nikel köpük üzerine kaplanan kompozit malzemenin kütlesini ifade etmektedir.

Farklı çinko kaynakları kullanılarak üretilen RGO/ZnO elektrotların $5 \mathrm{mV} / \mathrm{s}$ tarama hızında $6 \mathrm{M} \mathrm{KOH}$ çözeltisi içinde döngüsel voltamogram sonuçları Şekil 4'de gösterilmektedir. Elde edilen CV eğrilerinin şekli dikdörtgenimsi yapıdadır. Elektrot yapımında altlık olarak kullanılan Ni köpüğün kapasitans değeri son derece düşük olduğundan Ni köpüğe ait CV ölçümleri ve hesaplamaları bu çalışmada dikkate alınmamıştır. Farklı çinko kaynaklar kullanılarak üretilen RGO/ZnO kompozitlerinin Şekil 4'de gösterilen CV eğrilerinden yararlanarak hesaplanan spesifik kapasitans değerleri Tablo 1'de gösterilmiştir. Nitrat tuzundan elde edilen RGO/ZnO kompozit malzemesinin en yüksek kapasitans değerine sahip olduğu hesaplamalar sonucunda ortaya çıkmıştır. $\mathrm{Bu}$ durum nitrat tuzundan üretilen $\mathrm{RGO} / \mathrm{ZnO}$ kompozit malzemesinin yapısında oksijen içeren hidroksil grupların varlığından kaynaklanabilir. Kompozit malzeme de oksijen içeren grupların varlığı küçük boyutlu parçacıkların RGO yüzeyine tutunmasına katkı sağlar[21]. Şekil 2'deki XRD spektrumları incelendiğinde nitrat tuzu ile üretilen $\mathrm{RGO} / \mathrm{ZnO}$ kompozitin yapısında, asetat ve klorur tuzundan üretilen $\mathrm{RGO} / \mathrm{ZnO}$ kompozitlere göre hidroksil fazına ait piklerin daha belirgin olduğu gözlenmektedir.

Tablo 1. RGO/ZnO elektrotlarının $5 \mathrm{mV} / \mathrm{s}$ tarama hızında hesaplanan kapasitans değerleri

\begin{tabular}{lccccc}
\hline \multicolumn{1}{c}{ Çinko tuzu } & $\begin{array}{c}\text { Ortalama } \\
\mathbf{A k i m} \\
(\mathbf{m A})\end{array}$ & $\begin{array}{c}\text { Kütle } \\
(\mathbf{g})\end{array}$ & $\begin{array}{c}\text { Tarama } \\
\mathbf{h ı z} \\
(\mathbf{m V} / \mathbf{s})\end{array}$ & $\begin{array}{c}\text { Kapasitans } \\
(\mathbf{F} / \mathbf{g})\end{array}$ & $\begin{array}{c}\text { Kapasitans } \\
\text { değerindeki } \\
\text { azalma } \\
\text { miktarı(\%) }\end{array}$ \\
\hline $\mathrm{Zn}\left(\mathrm{NO}_{3}\right)_{2} \cdot 6 \mathrm{H}_{2} \mathrm{O}$ & 3.4 & 0.0129 & 5 & 52.71 & 39 \\
$\mathrm{ZnCl}$ & 2.8 & 0.0154 & 5 & 36.37 & 59 \\
$\mathrm{Zn}\left(\mathrm{CH}_{3} \mathrm{COO}\right)_{2 .} 2 \mathrm{H}_{2} \mathrm{O}$ & 1.9 & 0.0162 & 5 & 23.46 & 74 \\
\end{tabular}




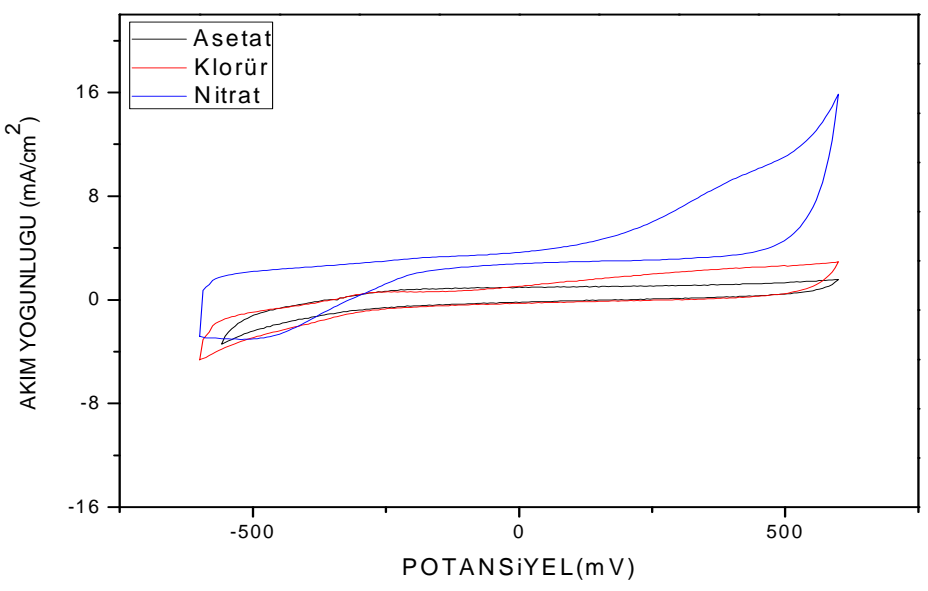

Şekil 4. Üretilen $\mathrm{RGO/ZnO}$ elektrotların döngüsel voltamogram grafikleri

Farklı çinko kaynakları kullanılarak üretilen RGO/ZnO elektrotların elektrokimyasal empedans değerlerini gösteren Nyquist empedans grafikleri Şekil 5'de gösterilmiştir. Nyquist empedans grafikleri elektrotların reel ve imajinal empedans değerlerini göstermektedir. Empedans ölçümleri 0,01 Hz ile $100 \mathrm{KHz}$ lik frekans aralığında gerçekleştirilmiştir. Yüksek frekansta, Nyquist grafiklerin reel ekseni (x-ekseni) kestiği nokta elektronun eşdeğer seri direncini (ESR) verir. Eşdeğer seri direnç elektrolit sıvısı (KOH), elektron direnci ( $\mathrm{RGO} / \mathrm{ZnO})$ ve elektrot ile akım taşıyıcı tellerin kontak direncini içerir [22]. Çinko nitrat, çinko klorür ve çinko asetat tuzlarından üretilen $\mathrm{RGO} / \mathrm{ZnO}$ elektrotların Nyquist grafiklerinden elde edilen ESR değerleri sırasıyla 14.1, 11.3 ve $11.5 \Omega$ civarında ölçülmüştür. Empedans ölçümlerinde düşük frekanslarda gözlenen ve elektrot ara yüzeyindeki yük transfer direncini ifade eden yarım çember şeklinde bir eğriye rastlanmamıştır. Bu durum elektrot ile elektrolit ara yüzeyinde hızlı yük transferi olduğunu ifade etmektedir.

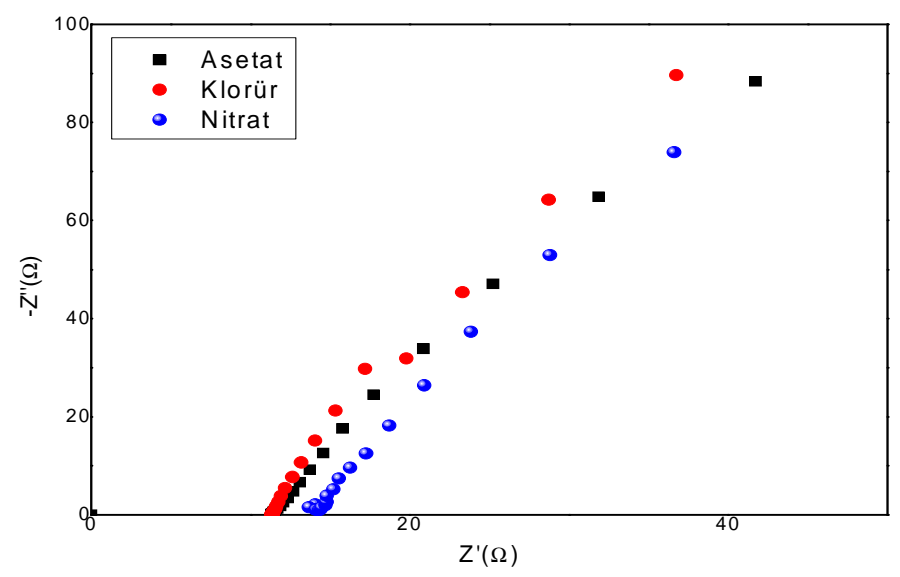

Şekil 5. Üretilen RGO/ZnO elektrotların Nyquist empedans spektrumları

Farklı çinko kaynakları kullanılarak sentezlenen RGO/ZnO elektrotların elektriksel yük dolma-boşalma (şarj-deşarj) eğrileri Şekil 6'da gösterilmiştir. Ölçümler 1,2 mA'lık sabit akım değeri altında 0-0,65V'luk değerler arasında gerçekleştirilmiştir. Dolma-boşalma eğrilerinden görüldüğü gibi çinko nitrat tuzundan üretilen 
elektrodun dolma-boşalma süresinin daha yüksek olduğu görülmüştür. Bu durum süper kapasitörler için istenen bir özelliktir. Şekil 6' daki deşarj eğrilerinin doğrusal parçaları, RGO/ZnO elektrotların çift katmanlı kapasitans davranışını gösterir. Bunun nedeni elektrot ile elektrolit ara yüzeyleri arasındaki yük ayrımıdır. Üretilen RGO/ZnO elektrotlarının spesifik kapasitans değerlerinin tarama hızına bağlı değişimi Şekil 7'de verilmiştir. Tüm elektrotlar için tarama hızı 5,10,50 ve $100 \mathrm{mV} / \mathrm{s}$ olacak şekilde seçilmiş ve tarama hızı arttıkça kapasitans değerinin azaldığı görülmüştür. RGO/ZnO elektrotların $5 \mathrm{mV} / \mathrm{s}$ tarama hızında stabilite testleri Şekil 8'de gösterilmiştir. Üretilen elektrotların, spesifik kapasitans değerleri 100 döngü alınarak hesaplanmış ve 100 döngü sonunda elde edilen kapasitans değerlerindeki \% azalma miktarları Tablo 1'de verilmiştir. Tablo 1'deki değerlerden görüldüğü gibi 100 döngü sonunda çinko nitrat tuzundan üretilen elektrotun \% azalma miktarı diğerlerine göre daha azdır. Bu sonuçlar çinko nitrat tuzundan yapılan $\mathrm{RGO} / \mathrm{ZnO}$ elektrotun daha uzun ömürlü olduğunu göstermektedir.

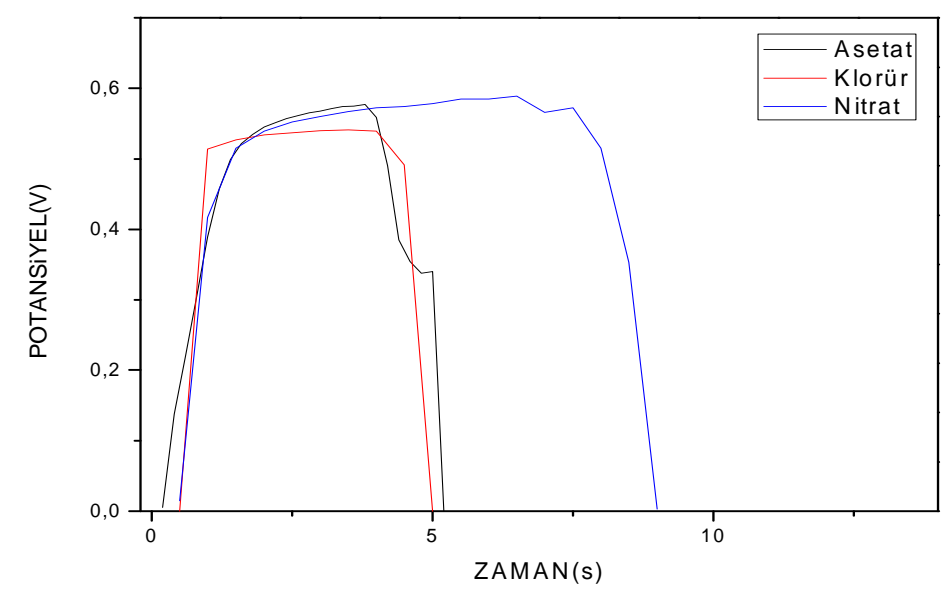

Şekil 6. Üretilen RGO/ZnO elektrotların dolma-boşalma eğrileri

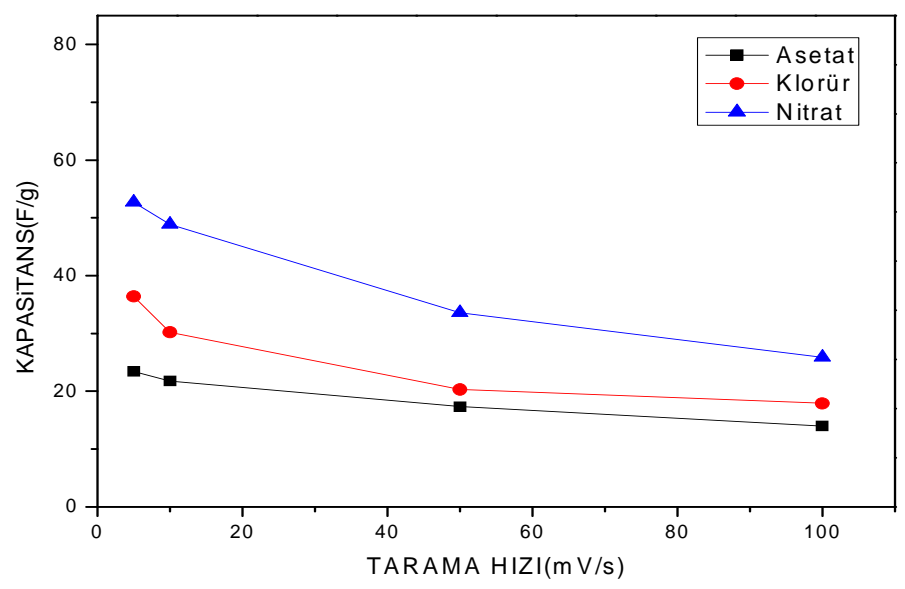

Şekil 7. Üretilen RGO/ZnO elektrotların değişik tarama hızlarına bağlı olarak kapasitans değerleri değişimi 


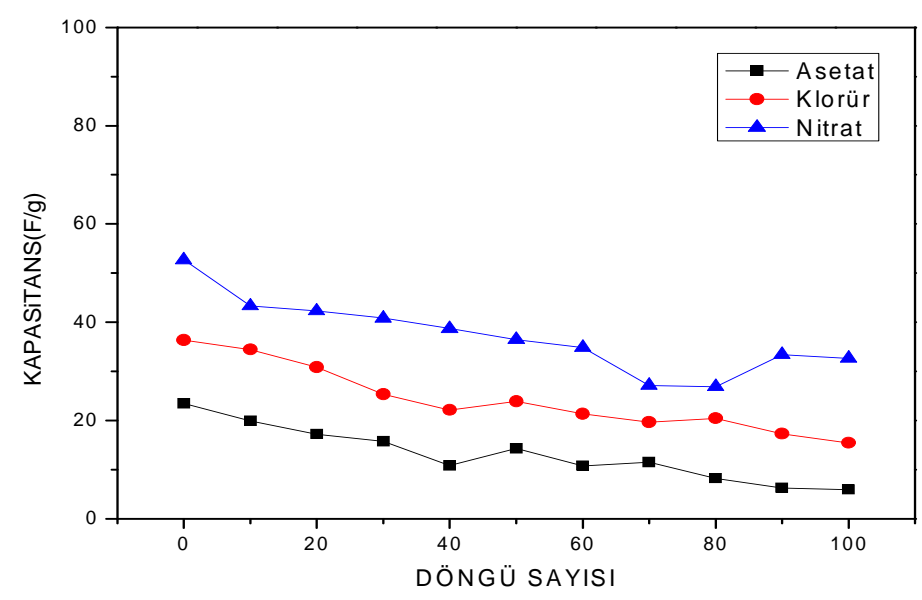

Şekil 8. Üretilen RGO/ZnO elektrotların döngü sayısına bağlı olarak kapasitans değerleri değişimi

\section{SONUÇLAR}

$\mathrm{Bu}$ çalışmada, farklı çinko kaynakları kullanılarak üretilen indirgenmiş grafen oksit/çinko oksit (RGO/ZnO) kompozit malzemeler hidrotermal yöntem kullanılarak oluşturulmuştur. Elde edilen $\mathrm{RGO} / \mathrm{ZnO}$ kompozitlerden süper kapasitör için elektrot yapımı gerçekleştirilmiş ve bu elektrotların kapasitans değerlerinin nasıl değişiklik gösterdiği incelenmiştir. Hidrotermal yöntem ile sentezlenen RGO/ZnO kompozit maddelerin XRD analizleri ve SEM fotoğrafları incelendiğinde wurtzide fazı ve kısmen hidroksit fazı içerdiği saptanmıştır. $\mathrm{Bu}$ durum $\mathrm{ZnO}$ parçacıkların GO çözeltisi içine konulduğunda tekrar hidroksit fazı geri kazanması ve kısmen simonkolleite faza dönüşmesi ile açıklanabilir. Farklı çinko kaynakları kullanılarak üretilen RGO/ZnO elektrotların kapasitans değerleri incelendiğinde çinko nitrat tuzundan üretilen elektrodun en yüksek kapasitans değerine $(52,71 \mathrm{~F} / \mathrm{g})$ sahip olduğu gözlenmiştir. Çinko nitrat tuzu ile üretilen $\mathrm{RGO} / \mathrm{ZnO}$ elektrodun kapasitans özelliğinin klorür ve asetat tuzları elde edilen $\mathrm{RGO} / \mathrm{ZnO}$ elektrotlardan daha iyi olmasının nedeni nitrat tuzundan elde edilen $\mathrm{RGO} / \mathrm{ZnO}$ kompozitin hidroksit yapı içermesi ile ilgili olabilir. Çinko nitrat tuzundan üretilen elektrodun 100 döngü sonunda spesifik kapasitans değerindeki \% azalma miktarı diğerlerine göre daha azdır. Bu durum çinko nitrat tuzundan üretilen $\mathrm{RGO} / \mathrm{ZnO}$ elektrodun daha uzun ömürlü olduğunu göstermektedir. Sonuç olarak çinko nitrat tuzu ile elde edilen $\mathrm{RGO} / \mathrm{ZnO}$ elektrodun yük taşımayı kolaylaştıran yüksek elektronegatif özelliğe sahip olduğu ve daha yüksek kapasitans özellik gösterdiği söylenebilir.

\section{KAYNAKLAR}

[1] Winter, M. \& Brodd, R.J. (2004). What are batteries, fuel cells and super capacitors. Chemical Reviews. $104,4245-4269$.

[2] Çalıker, A. \& Özdemir E. (2013). Modern Enerji Depolama Sistemleri ve Kullanm Alanlart. 5. Enerji Verimliliği ve Kalitesi Sempozyumu. Kartepe, Kocaeli: 175-179.

[3] Burke A. (2000). Ultracapacitors: Why, How and where is the techology. Journal of Power Sources. 91(1), 37-50.

[4] Miller, J.R. \& Simon, P. (2008). Electrochemical capacitors for energy management. Science. 321, 651652.

[5] Zhang, L.L. \& Zhao, X.S. (2009). Carbon-based materials as super capacitor elektrodes. Chemical Society Reviews. 38, 2520-2531. 
[6] Hou, J., Shao, Y., Ellis, M.W., Moore, R.B. \& Yi, B. (2011). Graphene-based electrochemical energy conversion and storage: fuel cells, super capacitors and lithium-ion batteries. 13,15384-15402.

[7] Wu, Z.S, Wang, D.W., Ren, W., Zhao, J., Zhou, G., Li, F. \& Cheng, H.M. (2010). Anchoring hydrous $\mathrm{RuO}_{2}$ on graphene sheets for high-performance electrochemical capacitors. Advanced Functional Materials. 19, 772-777.

[8] Fang, L., Zhang, B., Li, W., Huang, K. \& Zihang, Q. (2014). Fabrication of highly dispersed ZnO nanoparticles embedded in graphene nanosheets for high performance supercapacitors. Electrochimica Acta. 148, 164-169.

[9] Jayachandiran, J., Yesuraj, J., Arivanandhan, M., Raja, A., Suthanthiraraj, A.S., Jayavel, R. \& Nedumaran, D. (2018). Synthesis and electrochemical studies of $\mathrm{rGO} / \mathrm{ZnO}$ nanocomposite for supercapacitor application. Journal of Inorganic and Organometallic Polymers and Materials. 28 (5), 2046-2055.

[10] Mohan, R., Kıran, K.A.B.V., Naman, A. \& Subha, J. (2014). Studies on electrochemical properties of $\mathrm{ZnO} / \mathrm{rGO}$ nanocomposites as electrode materials for supercapacitors. Fullerenes, Nanotubes and Carbon Nanostructures. 23, 691-694.

[11] Hummers, M.S. \& Offeman, R.E. (1958). Preparation of graphitic oxide. Journal of the American Chemical Society. 80(6), 1339.

[12] Xu, C., Wang, X. \& Zhu, J. (2008). Graphene-metal particle nanocomposites. Journal of Physical Chemistry.112, 19841-19845.

[13] Cai, D. \& Song, M. (2007). Preparation of fully exfoliated graphite oxide nano platelets in organic solvents. Journal of Materials Chemistry. 17(35), 3678-3680.

[14] Lu, C.H. \& Yeh, C.H. (2000). Influence of hydrothermal conditions on the morphology and particle size of zinc oxide powder. Ceramics International. 26, 351-357.

[15] Palanikumar, L., Ramasamy, S., Hariharan, G. \& Balachandran, C. (2013). Influence of particle size of nano zinc oxide on the controlled delivery of amoxicillin. Applications Nano Science. 3, 441-451.

[16] Gusattia, M., Barrosoa, G. S., de Camposb, C.E.M., de Souzaa, D. A. R., Rosarioa, J., de A. Do, Limaa, R.B., Milliolia,C.C.,Silvaa, L.A.,Riellaa, H. G. \& Kuhnena, N.C. (2011). Effect of different precursors in the chemical synthesis of $\mathrm{ZnO}$ nano crystals. Materials Research. 14(2), 264-267.

[17] Alver, Ü. \& Tanriverdi, A. (2016). Boron doped $\mathrm{ZnO}$ embedded into reduced graphene oxide for electrochemical supercapacitors. Applied Surface Science. 378, 368-374.

[18] Baruah, S. \& Dutta, J. (2009). Hydrothermal growth of ZnO nanostructures. Science Technology of Advanced Materials. 10, 013001-013019.

[19] Yogamalar, N.R. \& Chandra Bose, A.C. (2011). Tuning the aspect ratio of hydrothermally grown ZnO by choice of precursor. Journal of Solid State Chemistry. 184, 12-20.

[20] Peng, Y. Ji, J. \& Chen, D. (2015). Ultrasound assisted synthesis of ZnO/reduced graphene oxidecomposites with enhanced photocatalytic activity andanti-photocorrosion. Applied Surface Science. 356, 762-768.

[21] Wang, H.L., Robinson, J.T., Diankov, G. \& Dai, .J. (2010). Nanocrystal growth on graphene with various degrees of oxidation. Journal of American Chemical Society. 132, 3270-3271.

[22] Zhang, J., Kong, L.B., Cai, J.J., Luo, Y.C. \& Kang, L. (2010). Nanoflake-like cobalt hydroxide/ordered mesoporous carbon composite for electrochemical capacitors. Journal of Solid State Electrochemistry. 14, 2065-2075. 